\title{
"Validación de máquina briqueteadora para el aprovechamiento de la cascarilla de café como combustible"
}

\author{
Karla Dávila - Docente Investigadora • Aura Amador / Fátima Morazán / Jader Rugama - Tesistas
}

\section{Resumen}

La investigación contó con el apoyo técnico y financiero de la Fundación para el Desarrollo Tecnológico Agropecuario y Forestal de Nicaragua (FUNICA) y su finalidad fue validar una máquina briqueteadora de tornillo helicoidal para el aprovechamiento de la cascarilla de café como combustible. Se determinaron las propiedades de la cascarilla de café, se caracterizaron las briquetas elaboradas con la máquina briqueteadora, comparándolas con las elaboradas artesanalmente, asimismo se establecieron las ventajas económicas de dicho equipo, y posteriormente se realizó un análisis comparativo entre las briquetas y la leña como combustible. Para elaborar estos análisis se ejecutaron varias actividades entre ellas: pruebas de ceniza, humedad, granulometría, análisis del funcionamiento del equipo, desarrollo de producto densificado (briquetas) con diferentes aglutinantes, pruebas de dióxido de carbono, poder calórico, y se realizó el cálculo de la inversión inicial, costos de producción de las briquetas. Las pruebas realizadas dieron como resultado que entre menor sea el tamaño de las partículas de la materia prima (cascarilla) se obtiene mayor calidad del producto densificado, sin embargo la máquina de tornillo helicoidal, resultó ser un equipo no funcional, debido al sistema de compactación que presentaba. Por éste y otros inconvenientes se descartó, por lo tanto se recurrió a dos prototipos de maquinaria como son el Molde de madera y la Prensa manual, este último presenta un sistema de compactación que permite obtener un producto de calidad al usar una mezcla de almidón cocido con cascarilla triturada. Con esto se procedió a realizar los cálculos de producción obteniendo que estos son mayores en la prensa, debido a su nivel de producción, en cambio en el molde son menores, pero su producto no es suficientemente compacto. Dentro del análisis comparativo entre la leña y la briqueta se encontró que ésta última presenta mayor poder calórico, genera menos dióxido de carbono, aspecto que podemos destacar desde el punto de vista ambiental.

Palabras Clave: Briquetas, cascarilla de café, aglutinantes, briqueteadora.

\section{Introducción}

Para el desarrollo de dicho estudio se tomó en cuenta que los desechos agrícolas como la madera, el aserrín, cascarilla de arroz, cascarilla de café, entre otros, pueden ocuparse de forma directa en los quehaceres del hogar, pero estos materiales sin ningún procesamiento previo arden con dificultad, producen mucho humo y no son apropiados para cocinar.

Uno de los mejores métodos para aprovechar dichos residuos consiste en la aglomeración de pequeñas partículas en briquetas, las cuales se fabrican a través del prensando utilizando algún material aglutinante para darles forma de ladrillos o cilindros y posteriormente usarlos en cocinas domésticas, o como combustible para hornos e intercambiadores de calor en la industria. De esa forma se aprovechan los desperdicios, se mejora la combustión, disminuyendo la contaminación ambiental y contando con un combustible económico.

Según (Camps\& Marcos, 2008) el tiempo de inflamabilidad de pellets y briquetas es similar o ligeramente superior al de las leñas. Las leñas presentan temperaturas y tiempos de inflamabilidad muy variables, pues dependen de la existencia o no de corteza, el tipo de corteza, el porcentaje de corteza, la 
disposición de la leña respecto al tipo del hogar y la superficie específica de la leña. Los biocombustibles forestales que más pronto se inflaman suelen ser las astillas y el carbón vegetal.

Por lo tanto, se consideró pertinente realizar una validación de un prototipo de máquina briqueteadora de tornillo helicoidal para el aprovechamiento de la cascarilla de café, con la finalidad de darle un valor agregado a este residuo (cascarilla de café) y de esta manera contribuir con la disminución de la contaminación ambiental, además de convertirlo en un combustible alternativo.

\section{Materiales y métodos}

La cascarilla de café fue sometida a una serie de pruebas físicas, con la finalidad de determinar el porcentaje de humedad, materia seca, cenizas y distribución granulométrica.

Las máquinas a validar fueron comparadas a fin de detectar debilidades que pudieran presentar durante el proceso de elaboración de briquetas, para esto se observó el comportamiento del equipo al ponerse en operación en condiciones de trabajo.

Otra de las etapas de la investigación fue la del desarrollo del producto densificado, para esto se realizaron diez repeticiones en cada uno de los equipos, con diferentes tipos de mezclas, que consistieron en aglomerantes, cascarilla de café molida y sin moler en diferentes proporciones, y otra mezcla sin aglomerantes. Esto tenía como propósito demostrar la influencia que tienen los aglomerantes en el proceso de elaboración de las briquetas, tanto en la compactación como al momento de realizarse la combustión del producto. Los aglomerantes propuestos para la investigación fueron la cal, almidón y arcilla, se decidió emplear estos productos ya que son considerados cementantes, es decir que ayudan a que el producto no se disgregue. Los porcentajes de materia prima y aditivos utilizados, se detallan a continuación:

- Tratamiento 1:50\% Cascarilla de café triturada, $29 \%$ agua y $21 \%$ cal.

- Tratamiento 2:67\% Cascarilla de café triturada

\section{y $33 \%$ agua.}

- Tratamiento 3:50\% Cascarilla de café triturada, $21 \%$ almidón en polvo, $29 \%$ agua

- Tratamiento 4:59\% Cascarilla de café triturada, $41 \%$ almidón cocido (mezcla de $7 \%$ almidón en polvo y $34 \%$ de agua).

- Tratamiento 5: 50 \% Cascarilla de café sin triturar, $29 \%$ agua y $21 \%$ cal.

- Tratamiento 6: 67\% Cascarilla de café sin triturar y $33 \%$ agua.

- Tratamiento 7: 50\% Cascarilla de café sin triturar, $21 \%$ almidón en polvo, $29 \%$ de agua.

- Tratamiento 8: 59\% Cascarilla de café sin triturar, $41 \%$ almidón cocido (mezcla de 7\% almidón en polvo y $34 \%$ de agua).

El producto obtenido de los equipos se sometió a diferentes pruebas. La metodología que se siguió para la realización de dichas pruebas se basa en investigación realizada por (Mora, 2007).

Para las briquetas se midieron las siguientes propiedades:

- Tiempo que duran encendidas las briquetas

- Las pruebas de emisión de $\mathrm{CO}_{2}$ se realizaron con el objetivo de determinar las ppm de

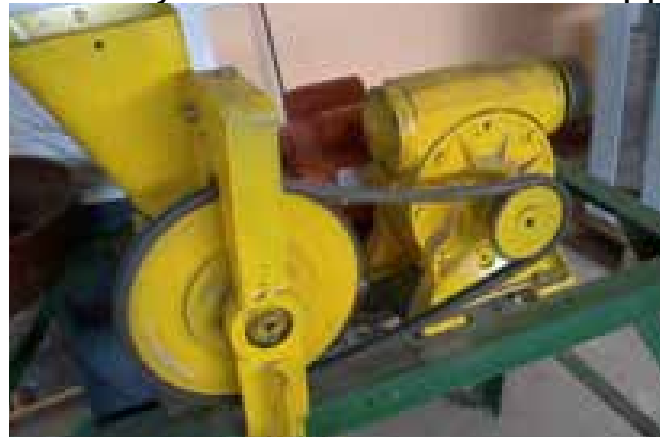

Figura 1. Máquina de tornillo helicoidal

gas que emanan las briquetas durante la combustión y luego establecer comparación con la cantidad que emana la leña.

- El poder calórico el cual se determinó mediante la prueba de agua hirviendo, conocida como The Water Boiling Test (WBT). 
Otro de los aspectos de la investigación fue la comparación entre las máquinas propuestas. Este análisis partió de los resultados obtenidos durante el desarrollo de las diferentes pruebas, además de considerar las capacidades de producción de cada uno de los equipos. A partir de esto se determinó la mejor alternativa de las tres opciones presentadas.

De igual manera se realizó un análisis comparativo entre la leña y las briquetas como combustible, aquí se incluyeron aspectos ambientales, incluyendo las emisiones de $\mathrm{CO}_{2}$.

\section{Resultados y discusión}

En la determinación de las propiedades de las cascarilla de café se encontró que el porcentaje de humedad es de $8.9 \%$, el porcentaje de ceniza fue de $0.6 \%$.

En relación al análisis granulométrico este permitió determinar la influencia que tienen el tamaño de las partículas durante la compactación o densificación de una biomasa en el caso de la cascarilla de café triturada se obtuvo la mayor cantidad en los tamices 20,30 y 100, pero la mayoría de los datos estaban en la malla 20.

En cuanto al análisis del funcionamiento de la máquina de tornillo helicoidal, ésta no presenta interruptor de apagado y encendido dificultando su manejo. Otras debilidades encontradas en este equipo es al momento de la alimentación de la mezcla, ya que regresa el material impidiendo la compactación y por ende la descarga del producto.

De las dificultades encontradas en este equipo se realizaron algunos cambios como reducir el diámetro del tornillo helicoidal, para mejorar el transporte del

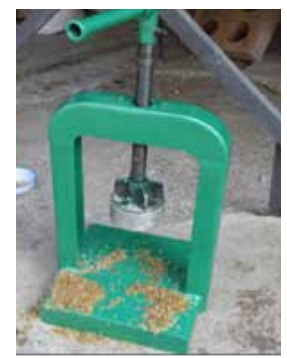

Figura 2. Prensa Manual material. Aún con esto, el equipo resultó ser no funcional, motivo por el cual se proponen otras tecnologías: La Prensa Manual de hierro y molde de madera.

En relación a la prensa manual de hierro, se realizaron las pruebas con las mezclas propuestas, se constató que el equipo cumple con la función básica para la elaboración del producto (briquetas).

Se considera que la función básica para la elaboración de briquetas es la compactación, esta se da mediante la aplicación de presión, para lo cual se obtuvo que la presión ejercida oscila entre 2.02 y $3.63 \mathrm{MPa}$.

Con respecto a las pruebas en el molde de madera, se constató que el equipo cumple con la función básica de la compactación de la materia, para la elaboración del producto (briquetas), a la cual se aplica una presión que según (Valderrama, Curo, Quispe,

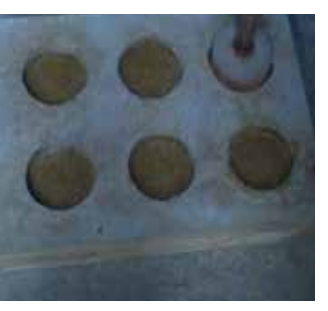

Figura 3. Molde de madera Llantoy, \& Gallo) que oscila entre 0.8 y $1.7 \mathrm{kPa}$.

En relación al producto densificado, las pruebas se realizaron con el molde de madera y la prensa manual. Obteniendo mejores resultados esta última, con la mezcla de cascarilla de café triturada, almidón cocido y agua, correspondiente al tratamiento 4.

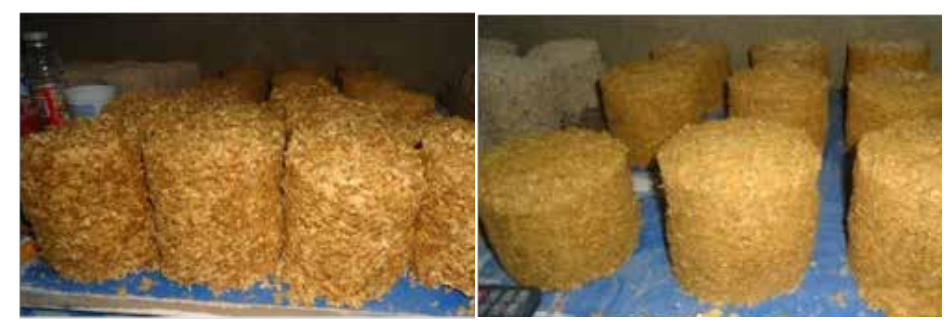

Figura 4. Briquetas elaboradas Figura 5. Briquetas elaboradas con el molde de madera con la prensa manual

Una vez obtenido el producto, estos fueron sometidos a pruebas físicas, donde se encontró un promedio de humedad del $7 \%$, cenizas del $1 \%$. En cuanto al tiempo que duran encendidas las briquetas, estas tienen un promedio de 15 minutos. Con respecto al $\mathrm{CO}_{2}$, se determinó que éste tenía una variabilidad entre 2800ppm y 4600 ppm, lo cual se comparó con el de la leña, donde la variabilidad es de 3822 ppm y 4800 ppm. También se comprobó que el agua hierve a los 20 minutos al utilizar las briquetas como combustibles. 
Con respecto a la determinación del nivel de producción de la máquina, en la de tornillo helicoidal no se determinó el nivel de producción, por los aspectos antes expresados. En cambio en el molde de madera se obtuvo que en una jornada de 8 horas se pueden elaborar 96 briquetas, una cada 5 minutos; en la prensa manual en cambio, se elaboran 69 briquetas, una cada 7 minutos, aunque cabe destacar que estas últimas presentan mejor calidad.

El costo de adquisición de los equipos es de $C \$ 4.800$ y $C \$ 1.500$ para la prensa manual y el molde de madera, respectivamente. Se determinó que el costo unitario en la prensa manual es de $C \$ 4,30$, en cambio en el molde el costo unitario es de $C \$ 3,54$.

\section{Conclusiones}

La materia prima utilizada se considera apta para la elaboración de briquetas, presentando $8.9 \%$ de humedad, $0.6 \%$ de cenizas y tamaño de partículas de 850UM, en el caso de la cascarilla triturada incidiendo significativamente en la densificación final del producto.

En cuanto al molde de madera se determinó que es un sistema de fácil alimentación, limpieza y alto nivel de producción, pero no se obtienen un producto de calidad, por su parte la Prensa manual se comprobó que es un equipo eficiente en cuanto a la compactación de biomasa, de fácil alimentación, manipulación, limpieza, no ocupa mucho espacio, presenta un sistema sencillo para la obtención del producto, aunque su nivel de producción es bajo en comparación con el molde de madera.

Así mismo la mejor mezcla resultó ser cascarilla de café triturada, almidón cocido y agua, esta fue evaluada en ambos equipos resultando que las briquetas elaboradas con la prensa son de mejor calidad, ya que el nivel de presión aplicado en estas tecnologías es distinto debido a su sistema de compactación.

Las briquetas en comparación con la leña presentan mayor poder calórico y generan menos dióxido de carbono, el tiempo de combustión es mayor.
Se determinó que el costo unitario es de $C \$ 4,30$ por briqueta para la prensa manual, en cambio en el molde de madera, su valor es de $C \$ 3,54$ por briqueta.

\section{Referencias}

Camps, M. M., \& Marcos, M. F. (2008). Los Biocombustibles. Madrid: Mundi Prensa.

Mora, S. M. (2007). Validación del funcionamiento de una briqueteadora de carbón vegetal. Chapingo: Universidad Autónoma de Chapingo, División de Ciencias Forestales.

Ortiz, L., Tejada, A., \& Vázquez, A. (2003). Aprovechamiento de la Biomasa Forestales Producida por la cadena Monte-Industria. Parte III: Producción de elementos Densificados. Galicia: Universidades de Santiago y Vigo.

Valderrama, A., Curo, H., Quispe, C., Llantoy, V., \& Gallo, J. (s. f.). Briquetas de residuos sólidos orgánicos como fuentes de energía calorífica en cocinas no convencionales. Lima-Perú: Centro de Desarrollo e Investigación en Termofluidos CEDIT. 